\title{
The Temperament and Character of Korean Male Conscripts with Military Maladjustment-A Preliminary Study
}

\author{
Kyoung-Ho Han $\bowtie$ and Sung-Bu Lee \\ Medical Department of 1596th Unit, Korea Army, Seoul, Republic of Korea
}

\begin{abstract}
Objective Recently, an increasing number of Korean male conscripts have been retiring because of military maladjustment despite the presence of qualifying medical and psychological screening tests in the Korean army. These problems suggest the presence of a common personality problem. To further examine this possibility, the present study used Cloninger's psychobiological model to investigate the temperament and character of soldiers suffering from military maladjustment.

Methods Seventy-nine maladjusted male conscripts and eighty-seven controls enrolled at the 1596th unit from April 2011 to June 2012 participated in the present study. To measure participant personality, we used the Korean version of the Temperament and Character Inventory, Revised-Short. We used logistic regression analysis to examine the association between TCI-RS scores and risk of military maladjustment.

Results The maladjustment group had a lower rank, socioeconomic status, education level, and a shorter duration of military service than the control group. The harm avoidance and self-transcendence scores were significantly higher in the maladjustment group, with lower scores for reward dependence, persistence, self-directedness, and cooperativeness scores. However, of these measures, only low cooperativeness was associated with an increased risk of military maladjustment.

Conclusion These results suggest that a low level of cooperativeness can predict military inadequacy. Maladjusted male conscripts may have different personality characteristics from normals. To validate our results, further follow-up or cohort studies with a larger sample will be required.

Psychiatry Investig 2013;10:131-136
\end{abstract}

Key Words Temperament, Character, Military psychiatry.

\section{INTRODUCTION}

In the Korean army, maladjusted male conscripts are transferred to the deliberative committee on military maladjustment when they severely has suffered from the distress of military life as a result of mental problem or illness without major psychiatric disorders although the intensive psychiatric interventions and extensive administrative actions. ${ }^{1}$ If the deliberative committee determines them to be unfit for service, they are admitted to a military service assessment unit to judge their suitability finally for the military over the course of 2 weeks. ${ }^{2}$

Received: July 31, 2012 Revised: November 19, 2012

Accepted: December 5, 2012 Available online: May 30, 2013

$\triangle$ Correspondence: Kyoung-Ho Han, MD

Medical Department of 1596th Unit, Korea Army, 20003-3 Namhyeon-dong, Gwanak-gu, Seoul 151-080, Republic of Korea

Tel: +82-2-524-6911, Fax: +82-2-527-7021, E-mail: drmindheist@gmail.com

(a) This is an Open Access article distributed under the terms of the Creative Commons Attribution Non-Commercial License (http://creativecommons.org/licenses/bync/3.0) which permits unrestricted non-commercial use, distribution, and reproduction in any medium, provided the original work is properly cited.
In 2009 and 2010, 486 and 776 Korean male conscripts, respectively, were admitted to that unit. In 2011, the number grew to $838 .^{3}$ This trend of increasing military maladjustment poses a serious problem because it has causes the party and his family members great anguish and also can prove devastating to the morale and force of the unit. Given that such conscripts passed the medical and psychological screening tests upon conscription, these later problems adapting to military life suggest that they have a common characteristic that renders them vulnerable to the stresses of the military lifestyle.

Personality is likely to be one of the common characteristic to cause the male conscripts maladjusted to military life. Because the personality trait is a feature that regarded as a predisposition or risk factor for several psychiatric diseases that also independently affect the prevalence and relapse of mental illness. ${ }^{4,5}$ Moreover, the basic concept of personality implies a unique individual adaptation to a broad range of personal and social situations. ${ }^{6}$

The notion of personality includes temperament and char- 
acter, with temperament defined as an individual manifestation of the level of a response to an emotional expression, mood change, and/or stimulus. Temperament is inherited, independent, and expressed mainly by both biochemical and genetic factors. Character, on the other hand, is a kind of unique adaptability to the environment that is transferred through generations and formed by the interaction of genetic differences and environmental influence. ${ }^{7,8}$

The Temperament and Character Inventory (TCI) has been used broadly to assess these aspects of personality. ${ }^{9}$ Originally developed by Cloninger, it consists of seven domains, defined as harm avoidance (HA), novelty seeking (NS), reward dependence $(\mathrm{RD})$, persistence $(\mathrm{P})$, self-directedness $(\mathrm{SD})$, cooperativeness (C), and self-transcendence (ST). ${ }^{10}$

The previous mainstream studies about military maladjustment sought to identify the factors related to unsuitability or focus of the soldiers with adjustment disorder. ${ }^{11-15}$

With regard to personality studies using military samples, Radamaken and colleagues ${ }^{16}$ found that early emotional trauma is related to adult personality impulse control problems and interpersonal behavior issues, of which SD and C are effective predictors. Elsass et al. ${ }^{17}$ found that TCI successfully predicted soldier vulnerability to military stress.

However, there are only a few studies of personality involving Korean male conscripts with maladjustment so severe that they were unable to continue active duty service. To address this gap in the literature, we compared the personality of male conscripts with military maladjustment in a military service assessment unit to that of normal soldiers using the TCI based on Cloninger's psychobiological theory conducting the cross-sectional, case-control study.

\section{METHODS}

\section{Participants}

The maladjusted male conscripts were recruited from the military service assessment department of the 1596th unit and controls were randomly recruited from the medics at the medical department of it between April 2011 and June 2012. The maladjusted male conscripts had been transferred to it after passing two levels of meticulous inspections by the deliberative committee on military maladjustment operated on division-size unit and the psychiatric department of military hospital respectively.

In this military service assessment department, all maladjusted male conscripts had been administered to the Structured Inventory of Malingered Symptomatology (SIMS) ${ }^{18}$ and the Miller Forensic Assessment of Symptoms Test (M-FAST) ${ }^{19}$ to detect the exaggerating or feigning the psychiatric symptoms as the routine work-up irrespective of this study, which are the useful screening instruments to rule out the false symptoms in forensic populations. ${ }^{20,21}$ It indicates malingering if the total SIMS scores are $>14$ or M-FAST $>7 .{ }^{18,19}$ The 23 maladjusted male conscripts were excluded before enrollment through this process. Our study was approved by the institute review board of the Korean Armed Medical Forces and the advantages and disadvantages of participation were explained to each male conscripts and their written informed consent was provided before enrollment.

The diagnoses were made by two military psychiatrists through the clinical interview according to the Diagnostic and Statistical Manual of Mental Disorders 4th edition (DSM-IV). Demographic variables were obtained from the interview and by review of the military medical charts and personnel records files. All psychiatric assessment of the participants were conducted for 2 weeks in this unit. 97 maladjusted male conscripts and 88 controls were included at the first time. Participants who suffered from mental retardation, suspicious malingering or malingering, or who expressed disagreement with the study were excluded. Of 185 male conscripts, 19 were excluded (12 suspicious malingering; 2 mental retardation; 4 disagreed with the study in the maladjustment group, and 1 control group participant that was a patient with adjustment disorder). The final analyzed sample consisted of 79 maladjusted male conscripts and 87 controls (total=166).

\section{Measurement}

We used the Korean Version of the Temperament and Character Inventory, Revised-Short (TCI-RS). ${ }^{22}$ The TCI is a 240item self-report questionnaire designed to evaluate four temperament (HA, NS, RD, P) and three character domains (SD, $\mathrm{C}, \mathrm{ST}$ ). NS involves in the degree of behavioral activation in response to novelty and signals of reward or relief from punishment. Behavioral inhibition occurs in response to signals of punishment or non-reward, with individual differences in inhibitablity characterized as being HA. RD represents succor and attachment, which strongly oppose feelings of rejection and disgust. $\mathrm{P}$ measures individual differences in behavioral maintenance without reinforcement to accomplish intellectual goals linked to communication and creativity. SD is the expression of a life guided by a sense of hope that allows a realistic acceptance of reality even if it appears to be inconsistent with past experiences. C measures the legislative function of judgment, which involves making rules that allow one to get along in a reasonable and flexible manner with others. ST measures the judicial function or depth of insight that allows one to know intuitively when legislative rules apply to a particular situation. ${ }^{10}$ The TCI-RS is a shorter, 140-item form of the TCI that is psychometrically reliable and valid. ${ }^{22}$ 


\section{Statistical analysis}

To compare the demographic and clinical characteristics between groups, we calculated the means, standard deviations, distributions and frequency for each variables. The normality of the continuous variables between groups were assessed by the Kolmogorov-Smirov test. The difference between duration of services, education were tested using MannWhitney tests. Fisher's exact test was used to examine differences between rank, religion, SES showing the expected frequency was less than 5 .

The scores of TCI-RS between two groups were compared by an analysis of covariance controlling for duration of service and education. To evaluate the predictive power of temperament and character yielding significant t-test results, we conducted a logistic regression analysis with adjustment for age, rank, SES, duration of education.

All analyses were performed using SPSS 18.0 with significance established at $\mathrm{p}<0.05$.

\section{RESULTS}

\section{Demographics}

The baseline demographics of the study groups partially differed (Table 1). In particular, those in the Maladjustment group had a lower rank, socioeconomic status (SES), and education level, and a shorter duration of military service than those in the control group. Adjustment disorders and personality disorders were the two most common diagnoses in the maladjustment group.

\section{Assessment of personality}

Table 2 shows the TCI-RS scores for the two groups. With the exception of the NS, the groups differed markedly in the TCI domains. In particular, the HA and ST scores were higher for the maladjusted participants while the RD, P, SD, and C scores were higher in the controls.

\section{Association between TCI-RS scores and risk of military maladjustment}

Table 3 shows the odds ratios and 95\% confidence intervals for military maladjustment according to the TCI-RS. The low C score was the only variable accounting for increased risk of military maladjustment. Also, this association remained significant after adjusting for age, rank, duration of education, and SES, none of which were significantly associated with military maladjustment.

\section{DISCUSSION}

This study showed that maladjusted male conscripts had
Table 1. Demographic and clinical characteristics of subjects

\begin{tabular}{|c|c|c|c|}
\hline & $\begin{array}{c}\text { Maladjustment } \\
\text { group } \\
\mathrm{N}=79(\%)\end{array}$ & $\begin{array}{c}\text { Control } \\
\text { group } \\
\mathrm{N}=87(\%)\end{array}$ & $\mathrm{p}$ \\
\hline \multicolumn{4}{|l|}{ Gender $^{\dagger}$} \\
\hline Male & $79(100)$ & $87(100)$ & 1.000 \\
\hline Female & $0(0)$ & $0(0)$ & \\
\hline Age $(y r s$, mean $\pm S D) \S$ & $21.1 \pm 1.3$ & $21.4 \pm 2.0$ & 0.181 \\
\hline $\begin{array}{l}\text { Duration of service }{ }^{\#} \\
\text { (months, mean } \pm \text { SD) }\end{array}$ & $9.5 \pm 4.4$ & $11.8 \pm 5.8$ & $0.013^{*}$ \\
\hline Rank $^{\ddagger}$ & & & $0.000^{* *}$ \\
\hline Private & $28(35.4)$ & $18(20.7)$ & \\
\hline Private first & $41(51.9)$ & $28(32.2)$ & \\
\hline Corporal & $9(11.4)$ & $31(35.6)$ & \\
\hline Sergeant & $1(1.3)$ & $10(11.5)$ & \\
\hline Marital status ${ }^{\ddagger}$ & & & 0.453 \\
\hline Single & $78(98.7)$ & $87(100)$ & \\
\hline Married & $1(1.3)$ & $0(0)$ & \\
\hline Religion ${ }^{\ddagger}$ & & & 0.123 \\
\hline Yes & $33(41.8)$ & $40(46.0)$ & \\
\hline No & $46(58.2)$ & $47(54.0)$ & \\
\hline Education (yrs, mean $\pm S D)^{\#}$ & $12.6 \pm 1.3$ & $13.1 \pm 1.0$ & $0.008^{*}$ \\
\hline S.E.S $\ddagger$ & & & $0.008^{*}$ \\
\hline Upper & $5(6.3)$ & $14(16.1)$ & \\
\hline Middle & $41(51.9)$ & $54(62.1)$ & \\
\hline Lower & $33(41.8)$ & $19(21.8)$ & \\
\hline Psychiatric diagnosis & & NA & NA \\
\hline Adjustment disorder & $34(43.0)$ & & \\
\hline Personality disorder & $18(22.9)$ & & \\
\hline Cluster A & $5(6.3)$ & & \\
\hline Cluster B & $7(8.9)$ & & \\
\hline Cluster C & $2(2.5)$ & & \\
\hline NOS & $4(5.1)$ & & \\
\hline Mood disorder & $10(12.7)$ & & \\
\hline Depressive disorder & $7(8.9)$ & & \\
\hline Bipolar disorder & $3(3.8)$ & & \\
\hline Anxiety disorder & $8(10.1)$ & & \\
\hline Panic disorder & $4(5.1)$ & & \\
\hline $\begin{array}{l}\text { Obsessive-compulsive } \\
\text { disorder }\end{array}$ & $2(2.5)$ & & \\
\hline Social anxiety disorder & $2(2.5)$ & & \\
\hline $\begin{array}{l}\text { Borderline intellectual } \\
\text { functioning }\end{array}$ & $4(5.1)$ & & \\
\hline Other & $5(6.3)$ & & \\
\hline
\end{tabular}

${ }^{*} \mathrm{p}<0.05,{ }^{* *} \mathrm{p}<0.001,{ }^{\dagger}$ chi-square test, ${ }^{\ddagger}$ Fisher's exact test, ${ }^{\S} \mathrm{T}$-test, \#Mann-Whitney test. NA: not applicable, SES: socioeconomic status, NOS: not otherwise specified 
Table 2. Comparison of TCI-RS scores between maladjustment and control groups ${ }^{\dagger}$

\begin{tabular}{lcccc}
\hline & Maladjustment group $($ mean \pm SD) & Control group $($ mean \pm SD) & $\mathrm{F}$ & 1.29 \\
\hline Novelty seeking & $35.9 \pm 11.4$ & $34.4 \pm 9.4$ & 69.89 & 0.258 \\
Harm avoidance & $56.9 \pm 18.2$ & $33.3 \pm 15.0$ & 62.52 & $0.000^{* *}$ \\
Reward dependence & $31.5 \pm 11.6$ & $46.9 \pm 11.1$ & 23.47 & $0.000^{* *}$ \\
Persistence & $33.8 \pm 16.0$ & $46.1 \pm 12.7$ & 54.29 & $0.000^{* *}$ \\
Self-directedness & $31.5 \pm 16.5$ & $50.6 \pm 14.0$ & 63.88 & $0.000^{* *}$ \\
Cooperativeness & $41.1 \pm 13.4$ & $58.5 \pm 11.7$ & 6.94 & $0.000^{* *}$ \\
Self-transcendence & $23.4 \pm 11.9$ & $19.0 \pm 9.5$ & $0.009^{*}$ \\
\hline
\end{tabular}

${ }^{*} \mathrm{p}<0.05,{ }^{* *} \mathrm{p}<0.001$, ${ }^{\dagger}$ analysis of covariance controlling for duration of service and education. TCI-RS: Korean Version of Temperament and Character Inventory Revised-Short

Table 3. Unadjusted and adjusted odds ratios for TCI-RS scores to military maladjustment

\begin{tabular}{|c|c|c|c|c|}
\hline \multirow{3}{*}{ Variables } & \multicolumn{4}{|c|}{ Military maladjustment ${ }^{\dagger}$} \\
\hline & Unadjusted & Adjusted & \multirow{2}{*}{$\begin{array}{c}\text { Unadjusted } \\
\text { p-value }\end{array}$} & \multirow{2}{*}{$\begin{array}{c}\text { Adjusted } \\
\text { p-value }\end{array}$} \\
\hline & \multicolumn{2}{|c|}{ Odds ratio (95\% confidence interval) } & & \\
\hline \multicolumn{5}{|l|}{ TCI domains } \\
\hline Harm avoidance & $1.04(0.99-1.09)$ & $1.04(0.99-1.10)$ & 0.104 & 0.098 \\
\hline Reward dependence & $0.96(0.91-1.00)$ & $0.96(0.91-1.01)$ & 0.070 & 0.102 \\
\hline Persistence & $1.04(0.99-1.09)$ & $1.03(0.98-1.09)$ & 0.131 & 0.220 \\
\hline Self-directedness & $0.96(0.91-1.02)$ & $0.97(0.91-1.03)$ & 0.209 & 0.308 \\
\hline Cooperativeness & $0.93(0.89-0.98)$ & $0.94(0.90-0.99)$ & $0.003^{*}$ & $0.016^{*}$ \\
\hline Self-transcendence & $1.04(0.99-1.10)$ & $1.03(0.98-1.08)$ & 0.104 & 0.209 \\
\hline Other variables & NA & & NA & \\
\hline Age & & $1.05(0.78-1.42)$ & & 0.749 \\
\hline \multicolumn{5}{|l|}{ Rank } \\
\hline Sergeant & & 1.00 & & 0.105 \\
\hline Corporal & & $1.24(0.11-14.20)$ & & 0.862 \\
\hline Private First & & $4.99(0.48-.53 .03)$ & & 0.179 \\
\hline Private & & $3.36(0.30-37.68)$ & & 0.326 \\
\hline \multicolumn{5}{|l|}{ SES } \\
\hline High & & 1.00 & & 0.537 \\
\hline Middle & & $1.72(0.34-8.80)$ & & 0.515 \\
\hline Low & & $2.48(0.45-13.68)$ & & 0.296 \\
\hline Duration of education & & $0.99(0.78-1.42)$ & & 0.749 \\
\hline
\end{tabular}

${ }^{*} \mathrm{p}<0.05$, ${ }^{\dagger}$ logistic regression was performed with adjustment for age, rank, SES, duration of education. TCI-RS: Korean Version of Temperament and Character Inventory Revised-Short, TCI: Korean Version of Temperament and Character Inventory, NA: not applicable, SES: socioeconomic status

different demographic and personality characteristics from normal male conscripts. In particular, low C scores significantly predicted risk of military maladjustment.

The maladjusted group had a lower SES and a lower level of education than the controls. This is important given that low SES has been identified as a risk factor for several mental disorders including personality disorder. ${ }^{23-26}$ However, this finding is inconsistent in military samples. ${ }^{27-29}$ These discrepancies may be attributable to the screening tests used during recruit- ing, thus leading to a decrease in the SES differences.

The level of education has also been inconsistent in previous military studies. ${ }^{29-31}$ However, most studies on Korean male conscripts indicate that a lower level of education predicts a greater likelihood of psychological disturbances and psychiatric problems. ${ }^{27,28,32}$ Studies with a larger sample and a robust design may be required to clarify this discrepancy.

Consistent with previous studies, ${ }^{11,33}$ male conscripts with maladaptation or psychiatric illness had lower ranks. In the 
Korean army, promotion to the upper ranks is allowed without serious disqualification. Male conscripts with adjustment problems or psychiatric disorders may not qualify for promotion. ${ }^{34}$ It is therefore natural that rank positively correlates with the duration of service in our study.

The maladjusted participants were found to have more pathological personality characteristics than control participants with the exception of NS. Measures of HA and ST were higher for the maladjusted group while $\mathrm{RD}, \mathrm{P}, \mathrm{SD}$, and $\mathrm{C}$ scores were lower. These results are similar to those of previous research. ${ }^{16}$

The NS domain exhibited no significant difference between the groups. Both group had similar degree of behavioral activation in response of novelty and reward during military life with repetitive, regulated, and plain patterns whichever unit the male conscript was in. Accordingly, we assumed that they would have different responses to the identical stimuli in aspects of emotion, cognition and behavior, eventually these differences might be expressed as follows; the maladjustment group would attempt to leave military life, and the normal group would search for satisfaction within a given circumstance.

High HA scores reflect fearful, pessimistic, shy characteristics while low SD reflect blaming, aimless and self-defeating. Depression has been with correlated with high HA scores and Low SD scores in the previous studies. ${ }^{35-37}$ Unlike depression, it has been reported that low $\mathrm{RD}$ and $\mathrm{C}$ scores are specific to anxiety disorder. ${ }^{38,39}$ These findings has been suggested that male conscripts with maladjustment would have negative emotions such as depression and anxiety.

Low P scores reflect unstable, underachieving performance in the face of frustration. High ST scorers are highly likely to be associated with in schizophrenia, bipolar disorder, and cluster A personality traits. ${ }^{10}$ Low $\mathrm{C}$ scores were the only predictor of increased risk of military maladjustment. This finding is in concordance with other studies finding that low $\mathrm{C}$ or SD scores are important predictors of the incidence of personality disorders, especially when the individual had a very low C score. ${ }^{16,40,41}$

$\mathrm{C}$ reflects the ability to collaborate, work with others, and accept and support them. In other words, a low $\mathrm{C}$ score means low sociality. ${ }^{10}$ Thus, deficient sociality seems to be the most essential psychopathology signaling poor suitability for the military life. Moreover, these results suggest that $\mathrm{C}$ may be a predictor of military adjustment and a useful screening tool for conscription.

All male conscripts can serve in the military after qualifying for the medical and psychological tests. Additionally, although great steps are taken at multiple levels to facilitate adaptation to military demands for several months before admission to a military service assessment unit, many nonetheless failed to adjust. Accordingly, we assumed that these maladjusted male conscripts have vulnerable, fixed personalities making them unsuitable for the military, personalities that are not otherwise detected under the current screening system.

Our study had several limitations. First, our preliminary study had the small sample size, which can lead to have low statistical power. This weakness may have biased the results in the logistic regression analysis because it's likely not to detect relatively weak association between TCI and military maladjustment. Second, the present study was a cross-sectional study not rendering causal inference impossible. These results should therefore be confirmed using cohort or prospective studies that are potentially more reliable. Third, the maladjusted male conscripts had different psychiatric diagnoses and would be in a wide range of mood state individually that had impact on the TCI. These heterogeneity between subjects made it difficult to interpret the our results of TCI. Fourth, the psychosocial factors such as developmental history in adolescence, coping skills to stress, social support system were not thoroughly investigated. It is important to evaluate these factors because they may have an effect on the susceptibility to military maladjustment.

Thus, the generalization of these results to other military populations may be limited. A follow-up or cohort study with a larger sample should be conducted in the future.

Despite these limitations, the present study was to our knowledge the first study to investigate the personality of severely maladjusted male conscripts in Korea. Our results suggest that the assessment of personality through the TCI can help identify maladaptive soldiers early on, thereby providing a useful complement to the current conscription screening system. Accordingly, we expect that such enhanced detection will contribute to the strengthening and reinforcement of morale in the Korean military.

\section{REFERENCES}

1. Republic of Korea Army, Regulation. No. 113. Chapter 3: Section 5; Article 56. Enforcement Date Dec 1st, 2011.

2. Republic of Korea Army, Regulation. No. 160. Chapter 4: Section 1; Article 36. Enforcement Date Jun 6th, 2012.

3. Ministry of National Defense Republic of Korea. 1st Suicide Prevention Seminar. Seoul, Korea. Apr 20th, 2012.

4. Christensen MV, Kessing LV. Do personality traits predict first onset in depressive and bipolar disorder? Nord J Psychiatry 2006;60:79-88.

5. Bond AJ. Neurotransmitters, temperament and social functioning. Eur Neuropsychopharmacol 2001;11:261-274.

6. Word Health Organization. Lexicon of Psychiatric and Mental Health Terms. Geneva: World Health Organization; 1994.

7. Cloninger CR, Svrakic DM, Przybeck TR. A psychobiological model of temperament and character. Arch Gen Psychiatry 1993;50:975-990.

8. Cloninger CR. A unified biosocial theory of personality and its role in 
the development of anxiety states. Psychiatric Dev 1986;4:167-226.

9. Svrakic DM, Draganic S, Hill K, Bayon C, Przybeck TR, Cloninger CR. Temperament, character, and personality disorders: etiologic, diagnostic, treatment issues. Acta Psychiatr Scand 2002;106:189-195.

10. Cloninger CR, Przybeck TR, Svrakic DM. The Temperament and Character Inventory (TCI): A Guide to Its Development and Use. Washington University, St Luis; Missouri: Center for Psychobiology of Personality; 1994.

11. Fiedler N, Ozakinci G, Hallman W, Wartenberg D, Brewer NT, Barrett $\mathrm{DH}$, et al. Military deployment to the Gulf War as a risk factor for psychiatric illness among US troops. Br J Psychiatry 2006;188:453-459.

12. Warner CH, Appenzeller GN, Parker JR, Warner CM, Hoge CW. Effectiveness of mental health screening and coordination of in-theater care prior to deployment to Iraq: a cohort study. Am J Psychiatry 2011;168: 378-385.

13. Mazokopakis EE, Vlachonikolis IG, Sgantzos MN, Polychronidis IE, Mavreas VG, Lionis CD. Mental distress and sociodemographic variables: a study of Greek warship personnel. Mil Med 2002;167:883-888.

14. Hansen-Schwartz J, Kijne B, Johnsen A, Andersen HS. The course of adjustment disorder in Danish male conscripts. Nord J Psychiatry 2005;59:193-197.

15. Jeong WC, Park YJ. Overview of Research trends in military service adjustment of soldiers in Korea. Korean Youth Res 2011:18;49-71.

16. Rademaker AR, Vermetten E, Geuze E, Muilwijk A, Kleber RJ. Self-reported early trauma as a predictor of adult personality: a study in a military sample. J Clin Psychol 2008;64:863-875.

17. Elsass WP, Fiedler E, Skop B, Hill H. Susceptibility to maladaptive responses to stress in basic military training based on variants of temperament and character. Mil Med 2001;166:884-888.

18. Edens JF, Otto RK, Dwyer T. Utility of the structured inventory of malingered symptomatology in identifying persons motivated to malinger psychopathology. J Am Acad Psychiatry Law 1999;27:387-396.

19. Miller HA. Miller Forensic Assessment of Symptoms Test(M-FAST): Professional Manual. Odessa, FL: Psychological Assessment Resources; 2001.

20. Lewis JL, Simcox AM, Berry DT. Screening for feigned psychiatric symptoms in a forensic sample by using the MMPI-2 and the structured inventory of malingered symptomatology. Psychol Assess 2002;14:170176.

21. Jackson RL, Rogers R, Sewell KW. Forensic applications of the Miller Forensic Assessment of Symptoms Test (MFAST): screening for feigned disorders in competency to stand trial evaluations. Law Hum Behav 2005;29:199-210.

22. Lee SH, Hwang ST. Construct Validity of the TCI-RS (Temperament and Character Inventory-Revised-Short Version): Comparing temperament and character with depression and anxiety in Korean undergraduates. Korean J Clin Psychol 2009;28:533-548.

23. McLaughlin KA, Breslau J, Green JG, Lakoma MD, Sampson NA, Zaslavsky AM, et al. Childhood socio-economic status and the onset, persistence, and severity of DSM-IV mental disorders in a US national sample. Soc Sci Med 2011;73:1088-1096.

24. Fischer C, Yeung E, Hansen T, Gibbons S, Fornazzari L, Ringer L, et al. Impact of socioeconomic status on the prevalence of dementia in an inner city memory disorders clinic. Int Psychogeriatr 2009;21:10961104.

25. Torgersen S, Kringlen E, Cramer V. The prevalence of personality disorders in a community sample. Arch Gen Psychiatry 2001;58:590-596.

26. Werner S, Malaspina D, Rabinowitz J. Socioeconomic status at birth is associated with risk of schizophrenia: population-based multilevel study. Schizophr Bull 2007;33:1373-1378.

27. Seo MK, Song HI, Rho GS, Lee KH, Yang JI, Sin DS. A study about risk factors and frequency of admission of adjustment disorder patients. J Korean Mil Med Assoc 2001;32:20-21.

28. Kim JH, Kang SH, Ye BS, Hwang HK, Suh JW, Chai GJ, et al. Psychiatric evaluation of maladaptive male conscripts in a division of the republic of Korean army: focus on green camp participants. Anxiety Mood 2010;6:131-136.

29. Yan J, Wang LJ, Cheng Q, Miao DM, Zhang LY, Yuan SP, et al. Estimated mental health and analysis of relative factors for new Chinese recruits. Mil Med 2008;173:1031-1034.

30. Bramsen I, Dirkzwager AJ, van der Ploeg HM. Predeployment personality traits and exposure to trauma as predictors of posttraumatic stress symptoms: a prospective study of former peacekeepers. Am J Psychiatry 2000;157:1115-1119.

31. Klemanski DH, Mennin DS, Borelli JL, Morrissey PM, Aikins DE. Emotion-related regulatory difficulties contribute to negative psychological outcomes in active-duty Iraq war soldiers with and without posttraumatic stress disorder. Depress Anxiety 2012;29:621-628.

32. An HJ, Kwon SC, Kim HM. Factors that influence non-combat military soldiers' suicidal ideation. J Korean Acad Psychiatr Ment Health Nurs 2010;19:299-306.

33. Bachynski KE, Canham-Chervak M, Black SA, Dada EO, Millikan $\mathrm{AM}$, Jones BH. Mental health risk factors for suicides in the US Army, 2007-8. Inj Prev 2012;18:405-412.

34. Republic of Korea Army Regulation. No. 113. Chapter 3: Section 4; Article 40. Enforcement Date, Dec 1st, 2011.

35. Farmer A, Mahmood A, Redman K, Harris T, Sadler S, McGuffin P. A sib-pair study of the Temperament and Character Inventory scales in major depression. Arch Gen Psychiatry 2003;60:490-496.

36. Josefsson K, Merjonen P, Jokela M, Pulkki-Råback L, KeltikangasJärvinen L. Personality Profiles Identify Depressive Symptoms over Ten Years? A Population-Based Study. Depress Res Treat 2011;2011:431314.

37. Lövdahl H, Bøen E, Falkum E, Hynnekleiv T, Malt UF. Temperament and character in patients with bipolar II disorder and recurrent brief depression. Compr Psychiatry 2010;51:607-617.

38. Lu X, Chen Z, Cui X, Uji M, Miyazaki W, Oda M, et al. Effects of temperament and character profiles on state and trait depression and anxiety: a prospective study of a Japanese youth population. Depress Res Treat 2012;2012:604684.

39. Kim SJ, Kang JI, Kim CH. Temperament and character in subjects with obsessive-compulsive disorder. Compr Psychiatry 2009;50:567-572.

40. Fonagy P, Gergely G, Jurist EL, Target M. Affect Regulation, Mentalization, and the Development of the Self. New York: Other Press; 2008.

41. Richter J, Brändström S. Personality disorder diagnosis by means of the Temperament and Character Inventory. Compr Psychiatry 2009;50:347352. 